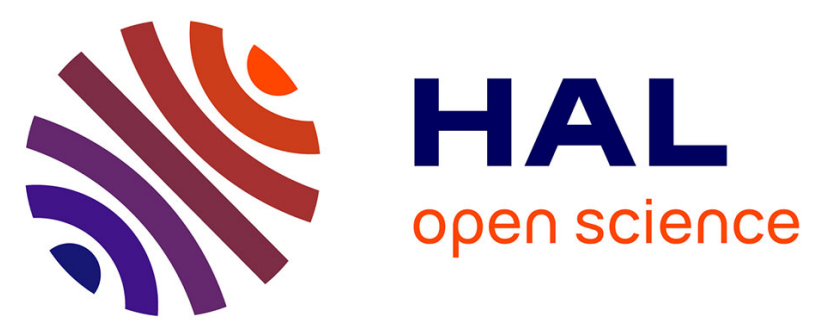

\title{
Plasma PCSK9 concentrations during the course of nondiabetic chronic kidney disease: Relationship with glomerular filtration rate and lipid metabolism
}

Marion Morena, Cédric Le May, Leila Chenine, Lucie Arnaud, Anne-Marie

Dupuy, Matthieu Pichelin, Hélène Leray-Moragues, Lotfi Chalabi, Bernard Canaud, Jean-Paul Cristol, et al.

\section{To cite this version:}

Marion Morena, Cédric Le May, Leila Chenine, Lucie Arnaud, Anne-Marie Dupuy, et al.. Plasma PCSK9 concentrations during the course of nondiabetic chronic kidney disease: Relationship with glomerular filtration rate and lipid metabolism. Journal of clinical lipidology, 2017, 11 (1), pp.87-93. 10.1016/j.jacl.2016.10.005 . hal-01763117

\section{HAL Id: hal-01763117 \\ https://hal.science/hal-01763117}

Submitted on 18 Dec 2019

HAL is a multi-disciplinary open access archive for the deposit and dissemination of scientific research documents, whether they are published or not. The documents may come from teaching and research institutions in France or abroad, or from public or private research centers.
L'archive ouverte pluridisciplinaire HAL, est destinée au dépôt et à la diffusion de documents scientifiques de niveau recherche, publiés ou non, émanant des établissements d'enseignement et de recherche français ou étrangers, des laboratoires publics ou privés. 


\title{
Plasma PCSK9 concentrations during the course of nondiabetic chronic kidney disease: Relationship with glomerular filtration rate and lipid metabolism
}

\author{
Marion Morena, PhD, Cédric Le May, PhD, Leila Chenine, MD, Lucie Arnaud, BS, \\ Anne-Marie Dupuy, MD, PhD, Matthieu Pichelin, PharmD, \\ Hélène Leray-Moragues, MD, Lotfi Chalabi, MD, Bernard Canaud, MD, \\ Jean-Paul Cristol, MD, PhD, Bertrand Cariou, MD, PhD*
}

Département de Biochimie et Hormonologie, CHU de Montpellier, Montpellier, France (Drs Morena, Dupuy, and Cristol); Institut de Recherche et de Formation en Dialyse, Montpellier, France (Drs Morena, Canaud, and Cristol); PhyMedExp, Université de Montpellier, INSERM U1046, CNRS UMR 9214, Montpellier, France (Drs Morena and Cristol); L'Institut du Thorax, INSERM, CNRS, UNIV Nantes, Nantes, France (Drs Le May and Arnaud); Service de Néphrologie, CHU de Montpellier, Montpellier, France (Drs Chenine and Leray-Moragues); L'Institut du Thorax, INSERM, CNRS, UNIV Nantes, CHU Nantes, France (Drs Pichelin and Cariou); AIDER, Montpellier, France (Dr Chalabi); Université de Montpellier, Néphrologie, Montpellier, France (Dr Canaud); and Fresenius Medical Care, Bad Homburg, Germany (Dr Canaud)

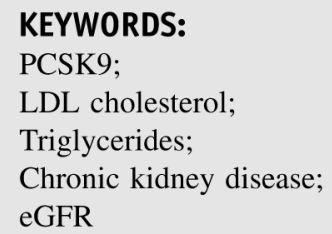

BACKGROUND: The association between proprotein convertase subtilisin/kexin type 9 (PCSK9), a critical regulator of low-density lipoprotein (LDL) metabolism, and kidney function is a matter of debate.

OBJECTIVE: We aimed to assess the association of circulating PCSK9 concentrations with both glomerular filtration rate (eGFR) and serum lipid parameters in nondiabetic patients with chronic kidney disease (CKD).

METHODS: Fasting plasma PCSK9 concentrations were measured by ELISA in 94 nondiabetic nondialysis CKD (ND-CKD) patients not receiving statins, at different stages of CKD.

RESULTS: Plasma PCSK9 levels were associated neither to eGFR $(P=.770)$ nor to proteinuria $(P=.888)$ at several stages of CKD. In addition, plasma PCSK9 levels did not vary significantly between the different CKD stages. Plasma PCSK9 concentrations were positively correlated with apolipoprotein $\mathrm{B}(\mathrm{r}=0.221 ; P=.03)$ and triglycerides $(\mathrm{r}=0.211 ; P=.04)$ but not with total cholesterol, calculated LDL-cholesterol, HDL cholesterol, lipoprotein(a), or CRP.
This work was partly supported by a grant from Ministère de la Santé (PHRC-UF 7853), the Fondation Leducq (grant no. 13CVD03) (Transatlantic Network of Excellence Programme: "The function and regulation of PCSK9: a novel modulator of LDLR activity," to BC) and Fundazione Cariplo (to BC). No additional external funding was received for this study. The funders had no role in study design, data collection and analysis, decision to publish, or preparation of the manuscript.
* Corresponding author. Clinique d'Endocrinologie, Hôpital Guillaume \& René Laennec, Boulevard Jacques Monod, Saint-Herblain, 44093 Nantes Cedex 1, France.

E-mail address: bertrand.cariou@univ-nantes.fr

Submitted July 25, 2016. Accepted for publication October 7, 2016. 
CONCLUSION: In a homogeneous population of nondiabetic subjects without lipid-lowering therapy, plasma PCSK9 concentrations are not associated to eGFR at several stages of CKD. These data suggest that kidney function per se does not impact significantly PCSK9 metabolism.

\section{Introduction}

Cardiovascular $(\mathrm{CV})$ risk increases during the course of chronic kidney disease (CKD) and is further enhanced during renal replacement therapy. ${ }^{1-3}$ However, traditional risk factors such as hypertension, high low-density lipoprotein (LDL) cholesterol (LDL-C) levels, low high-density lipoprotein (HDL) cholesterol (HDL-C) levels, or smoking do not fully explain this elevated CV risk and a constellation of nontraditional risk factors including inflammation, oxidative stress, bone, and mineral disorders has emerged. $^{4,5}$ Uremia-related dyslipidemia is characterized by progressive qualitative and quantitative changes in lipid homeostasis, abnormalities in circulating lipoprotein composition, and metabolism impairment. During the course of CKD, a rise in triglycerides (TG) and very lowdensity lipoprotein-cholesterol (VLDL-C) is observed, whereas HDL-C decreases. LDL-C remains normal or slightly decreases. However, qualitative modifications of LDL occur resulting in an accumulation of small-dense LDL. ${ }^{6}$ Similarly, lipoprotein(a) $[\mathrm{Lp}(\mathrm{a})]$ is dramatically increased, being considered as an independent risk factor. The underlying mechanism of CKD-associated dyslipidemia is not fully understood, and nontraditional risk factors such as inflammation, insulin resistance, altered adipokines levels, or medications could be confounding factors. However, this large interplay between traditional and nontraditional risk factors may partly explain the relative inefficiency of statin therapy in CKD population.

Recently, proprotein convertase subtilisin/kexin type 9 (PCSK9), which promotes the degradation of LDL receptor (LDLR) by inhibiting its recycling to the plasma membrane, has emerged as a major regulator of lipid metabolism. ${ }^{7}$ Indeed, the mutations of PCSK9 gene resulting in a gain-of-function are associated with autosomal dominant hypercholesterolemia, whereas loss-of-function PCSK9 mutations are related to low LDL-C levels ${ }^{8}$ and low incidence of coronary events. ${ }^{9}$ After the development of human monoclonal antibodies directed against PCSK9 (PCSK9 $\mathrm{mAb}$ ), large meta-analysis demonstrated that PCSK9 $\mathrm{mAb}$ administration could dramatically decrease LDL$\mathrm{C}^{10,11}$ and also $\mathrm{Lp}$ (a) levels. ${ }^{12}$ Recently, it has been suggested that hypercholesterolemia observed in nephrotic syndrome or in end-stage kidney disease (ESKD) patients treated with peritoneal dialysis could be related to an increase in PCSK9. ${ }^{13-15}$ However, levels of PCSK9 during the course of CKD yielded conflicting results. Rogacev et al. ${ }^{16}$ analyzed the data of two large cohorts of patients from stage 2 to 4 , the CARE FOR HOMe and the LURIC cohorts and reported that PCSK9 level did not correlate with estimated glomerular filtration rate (eGFR). On the other hand, Abujrad et al. ${ }^{17}$ showed that LDL-C and PCSK9 levels were significantly decreased in hemodialysis (HD) patients with a positive correlation between the two parameters. Finally, Konarzewski et al. reported increased PCSK9 levels in CKD patients with an inverse correlation between plasma PCSK9 concentrations and eGFR. ${ }^{18}$ Because statin use and diabetes could influence PCSK9 levels, ${ }^{19-22}$ we decided to assess plasma PCSK9 levels in a population of nondiabetic nondialysis CKD (ND-CKD) patients not receiving statins, at different stages of CKD, except patients on hemodialysis.

\section{Material and methods}

\section{Ethics statement}

The study was conducted according to the principles of the Declaration of Helsinki and in compliance with International Conference on Harmonization/Good Clinical Practice regulations. According to the French Law, the study has been registered at "Ministère de la Santé et des Solidarités" after approval by the Montpellier University Hospital's ethics committee (Comité de Protection des Personnes Sud Méditerranée IV) with the following number DC-2008-417. All patients gave their written informed consent.

\section{Subjects}

Ninety four nondialysis CKD patients (namely 'ND$\mathrm{CKD}^{\prime}$ ) at various stages of kidney disease, issued from the outpatient general nephrology consultation of the Montpellier Lapeyronie university hospital were enrolled in this cross-sectional study. Inclusion criteria were age $\geq 18$ years, and presence of CKD defined by glomerular filtration rate (GFR) in agreement with the National Kidney Foundation $^{23,24}$ as either kidney damage or GFR $<60 \mathrm{~mL} /$ $\min / 1.73 \mathrm{~m}^{2}$ for $\geq 3$ months. Kidney damage was defined as pathologic abnormalities or markers of damage, including abnormalities in blood or urine tests or imaging studies. ND-CKD patients with diabetes and/or on statin therapy were excluded from the study. Blood and urine samples were collected as part of our regular CKD patient followup after a 12-hour fasting. 
For all subjects, medical history including age, gender, body weight, height, etiology of $\mathrm{CKD}$, diabetes mellitus, hypertension, and treatments was recorded.

\section{Laboratory measurements}

Blood samples were centrifuged, and supernatant was stored at $-80^{\circ} \mathrm{C}$ for processing of creatinine, TC, HDL-C, TG, Lp(a), apolipoprotein B (apoB), and PCSK9. In addition, measurement of proteins on a sample of urine collected over 24 hours was performed in ND-CKD patients.

Creatinine was measured by ID-MS traceable enzymatic method on a Cobas c502 apparatus (Roche Diagnostics, Mannheim Germany), ${ }^{25}$ and GFR was estimated using CKD-EPI equation. ${ }^{26}$ Use of ID-MS traceable enzymatic creatinine assay and CKD-EPI equation allows eGFR determination up to $90 \mathrm{~mL} / \mathrm{min} / 1.73 \mathrm{~m}^{2} 27$ or $120 \mathrm{~mL} / \mathrm{min} /$ $1.73 \mathrm{~m}^{2} 28 \mathrm{TC}$, HDL-C, and TG levels were measured by enzymatic colorimetric method (Roche Diagnostics, France). LDL cholesterol (LDL-C) was calculated by the Friedewald equation. Patients with plasma TG $\geq 4.5 \mathrm{mmol} / \mathrm{L}$ were excluded. $\mathrm{Lp}$ (a) and apo-B were analyzed by immunoturbidimetric assay (Roche Diagnostics, France). Urinary proteins were assessed by turbidimetry method (Roche Diagnostics, France). Plasma PCSK9 was determined by enzyme-linked immunosorbent assay (Circulex CY-8079, CycLex Co, Nagano, Japan).

\section{Statistical methods}

Characteristics of the population were described by using proportions for categorical variables and median and range for quantitative variables because their distributions were tested with the Shapiro-Wilk statistic and were mostly skewed.

Chi-square test was used to test the association between two categorical variables.

The comparisons of variables between groups were performed using nonparametric Kruskal Wallis and Mann-Whitney $U$ tests.

Simple regression analysis and the Spearman correlation coefficient ( $r$ ) were used to determine the relationships between quantitative variables.

Significance was set at $P<.05$. All analyses were carried out with Statview software, version 5.0 (SAS Institute Inc, Cary, NC).

\section{Results}

\section{Characteristics of CKD patients}

Clinical and biological characteristics for the patients are summarized in Table 1 . The main etiology for CKD was nephroangiosclerosis $(\approx 50 \%)$ following by glomerulonephritis and cystic renal disease. Owing to the exclusion
Table 1 Characteristics for ND-CKD patients

\begin{tabular}{lc}
\hline Parameter & ND-CKD \\
\hline $\mathrm{N}$ & 94 \\
Gender, male (\%) & $53(56.4 \%)$ \\
Age (years) & $69(25-95)$ \\
BMI (kg/m $\left.{ }^{2}\right)$ & $24.9(14.3-35.7)$ \\
Etiology of CKD (\%) & \\
$\quad$ Angiosclerosis and & $43(45.7 \%)$ \\
$\quad$ hypertensive nephropathy & $16(17.0 \%)$ \\
$\quad$ Glomerulonephritis & $15(16.0 \%)$ \\
$\quad$ Cystic renal disease & $3(3.2 \%)$ \\
Interstitial nephropathy & $17(18.1 \%)$ \\
$\quad$ Other cause & 0 \\
Diabetes mellitus (\%) & $81(86.2 \%)$ \\
Hypertension (\%) & $41.8(27.4-58.0)$ \\
Albumin (g/L) & $2.2(0.3-56.1)$ \\
C-reactive protein $(\mathrm{g} / \mathrm{L})$ &
\end{tabular}

ND-CKD, non-dialysis chronic kidney disease; LDL, low-density lipoprotein; HDL, high-density lipoprotein.

criteria, there was no case of diabetic glomerulosclerosis in ND-CKD patients. Plasma albumin levels were in the normal range, excluding nephrotic syndrome.

\section{Plasma PCSK9 is neither associated to eGFR nor to proteinuria at several stages of CKD}

As depicted in Figure 1, no correlation between plasma PCSK9 and both (A) eGFR (CKD-EPI; PCSK9 $=390.791$ $+0.211 \times \mathrm{eGFR} ; \mathrm{R} 2=0.001 ; P=.770)$ and $(\mathrm{B})$ proteinuria $($ PCSK9 $=388.415+40.76 \times$ urinary proteins $(\mathrm{g} / 24 \mathrm{~h}) ; \mathrm{R} 2=0.012 ; P=.888)$ was observed in NDCKD patients.

\section{Plasma PCSK9 concentrations do not vary at different stages of CKD}

Figure 2 depicts plasma levels of PCSK9 and lipid parameters in ND-CKD after splitting the group according to $\mathrm{CKD}$ stages (eGFR $\geq 60$ vs [60-30] vs [30-15] vs $\leq 15 \mathrm{~mL} / \mathrm{min}$ ). No significant changes in plasma PCSK9 as well as other lipid variables (TC, LDL-C, HDL-C, TG, and $\mathrm{Lp}(\mathrm{a})$ ) were observed, reinforcing the absence of a link between PCSK9 metabolism and CKD.

\section{Plasma PCSK9 is positively correlated with apo-B and triglycerides in ND-CKD patients}

Associations between plasma PCSK9 and lipid parameters in ND-CKD patients are listed in Table 2. A significant positive correlation was established between PCSK9 and both TG (rho $=0.211 ; P=.04$ ) and apo-B (rho $=0.221 ; P=.03$ ). In addition, there were some nonstatistically significant trends for positive correlations between PCSK9 and TC (rho $=0.187 ; P=.07$ ), LDL-C 

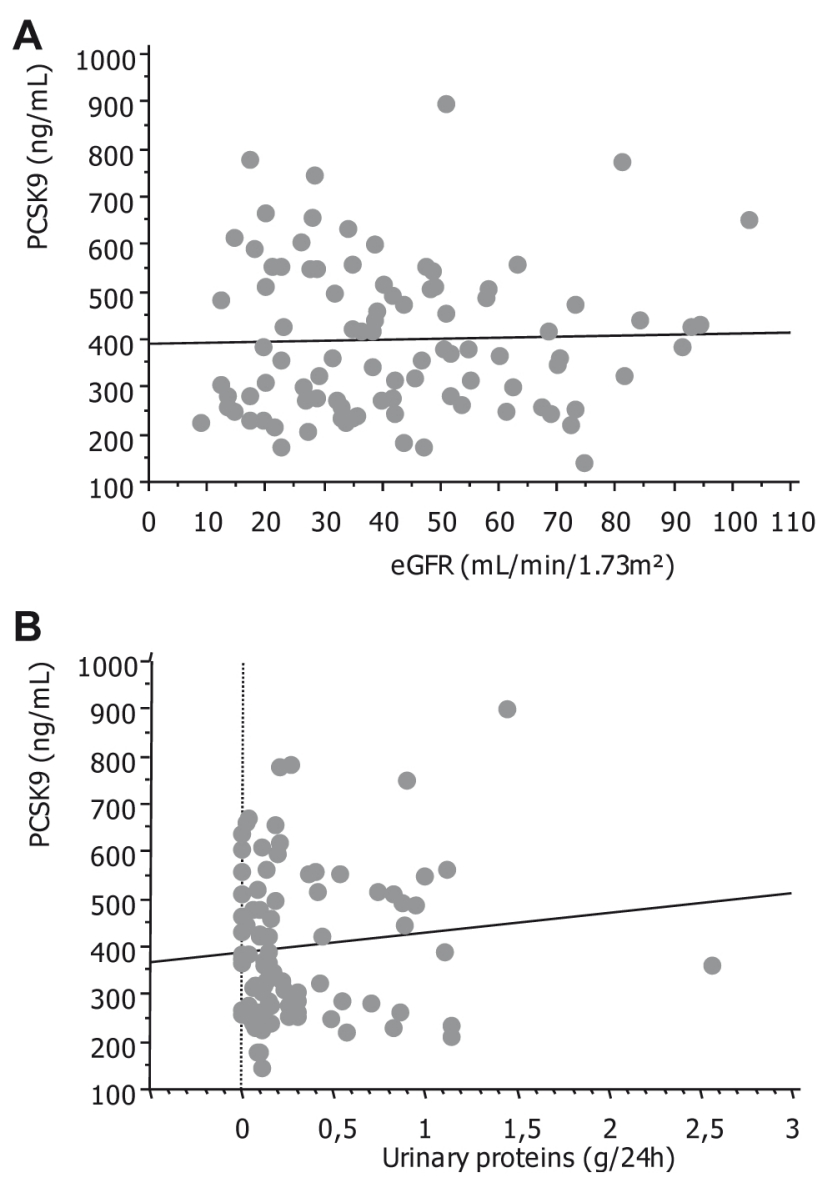

Figure 1 Plasma PCSK9 concentration is neither associated to eGFR (A) nor to proteinuria (B) at several stages of CKD. (A) Correlations between PCSK9 and eGFR (CKD-EPI; PCSK9 $(\mathrm{ng} / \mathrm{mL})=390.791+0.211 \times \mathrm{eGFR}\left(\mathrm{mL} / \mathrm{min} / 1.73 \mathrm{~m}^{2}\right) ;$ $\mathrm{R} 2=0.001 ; P=.770$ ). (B) Correlations between PCSK9 and urinary proteins $(\mathrm{g} / 24 \mathrm{~h})(\mathrm{PCSK} 9(\mathrm{ng} / \mathrm{mL})=388.415+40.76 \times$ urinary proteins $(\mathrm{g} / 24 \mathrm{~h}) ; \mathrm{R} 2=0.012 ; P=.888)$.

(rho $=0.186 ; P=.08$ ), and non-HDL-C (rho $=0.192$; $P=.06)$. In contrast, there was no trend for a relationship between PCSK9 and HDL-C or Lp(a).

\section{Discussion}

Our study clearly demonstrates that circulating PCSK9 levels are not influenced by the course of CKD in nondiabetic patients not receiving statins and without nephrotic proteinuria.

The lack of relationship observed here between PCSK9 and eGFR is in line with recent data reported by Rogacev et al. $^{16}$ from the CARE FOR HOMe and LURIC large ( $>1500$ patients) cohort studies. By contrast to our population, which only includes patients not receiving statins, $49 \%$ and $44 \%$ of patients in CARE FOR HOMe and LURIC studies respectively were under statin therapy. However, sensitivity analyses taking into account statin intake did not modify the results in these two cohorts. ${ }^{16}$ As statin treatment increases PCSK9 level via a stimulation of sterol response element binding protein-2 in the general population, ${ }^{29}$ use of statin is therefore an important confounder in the previous smaller studies. In the same way, increased PCSK9 levels have been reported in patients with diabetes and/or insulin resistance. ${ }^{21,22}$ To specifically address the effect of eGFR on plasma PCSK9 concentration, diabetic patients were carefully excluded from our study, whereas the previous studies included ones (around $40 \%$ of the participants) as well. ${ }^{16}$ Finally, no nephrotic proteinuria was observed in our predialysis patients. This metabolic disorder is associated with a dramatic increase in PCSK9 as shown in proteinuric patients and in experimental nephrotic syndrome. ${ }^{13,30}$ Very recently, it has been suggested that PCSK9 could be an important contributor to the nephrotic syndromeassociated hypercholesterolemia. ${ }^{15}$ Indeed, both global and liver-specific PCSK9 knockout mice exhibit reduced hypercholesterolemia and hypertriglyceridemia following experimentally induced nephrotic syndrome. ${ }^{15}$ To summarize, in our population of stage 1-5 CKD patients, a relatively small but homogeneous population due to the absence of main confounders (statin use, diabetes, or nephrotic proteinuria), we confirmed the lack of significant relationship between plasma PCSK9 levels and eGFR.

In contrast to what observed in non-CKD cohorts, ${ }^{21}$ the classical positive association between PCSK9 and LDL-C failed to reach statistical significance in CKD patients, despite a strong trend $(P=.08)$. On the other hand, significant positive relationships between PCSK9 and both TG and apo-B were observed in ND-CKD. This finding is in agreement with the report from Abujrad et al. in HD patients. ${ }^{17}$ As TG constitutes the main component of apo-B-VLDL particles, this metabolic pattern may be due to an increase in VLDL particles previously described in CKD. In addition, some evidence in mice $^{31,32}$ and human ${ }^{33,34}$ support the hypothesis that PCSK9 can modulate hepatic apo-B production under certain pathophysiological circumstances. Very recently, Sucajtys-Szulc et al. demonstrated in a rat model of CKD that chronic renal failure enhanced hepatic expression PCSK9, possibly through an HNF1 signaling pathway, as well as an increase of lipogenic enzymes, apo-B, and microsomal triglyceride transfer protein mRNA expression. ${ }^{35}$ In this rat CKD model, a clear positive correlation was found between circulating PCSK9 and TG concentrations $(\mathrm{r}=0.62, P<.01) .{ }^{35}$ Altogether, these data support the hypothesis that PCSK9 could contribute to the increased apo-B production observed in CKD. Alternatively, PCSK9 could also impair the clearance of TG-rich lipoproteins, a characteristic feature also observed in a previous in vivo lipoprotein kinetics study performed in CKD subjects, ${ }^{36}$ at least by down regulating the LDLR in the liver. ${ }^{37}$

One limitation of our study is the relatively small number of subjects that could have limit the statistical power to detect some significant association (between 

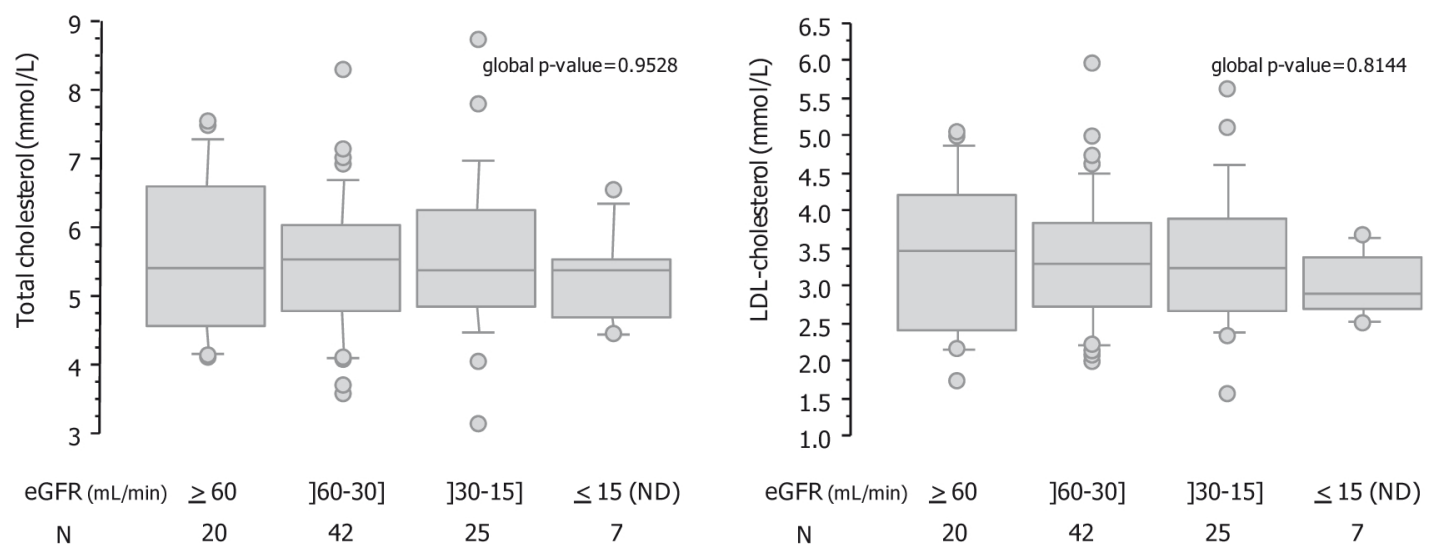

Triglycerides
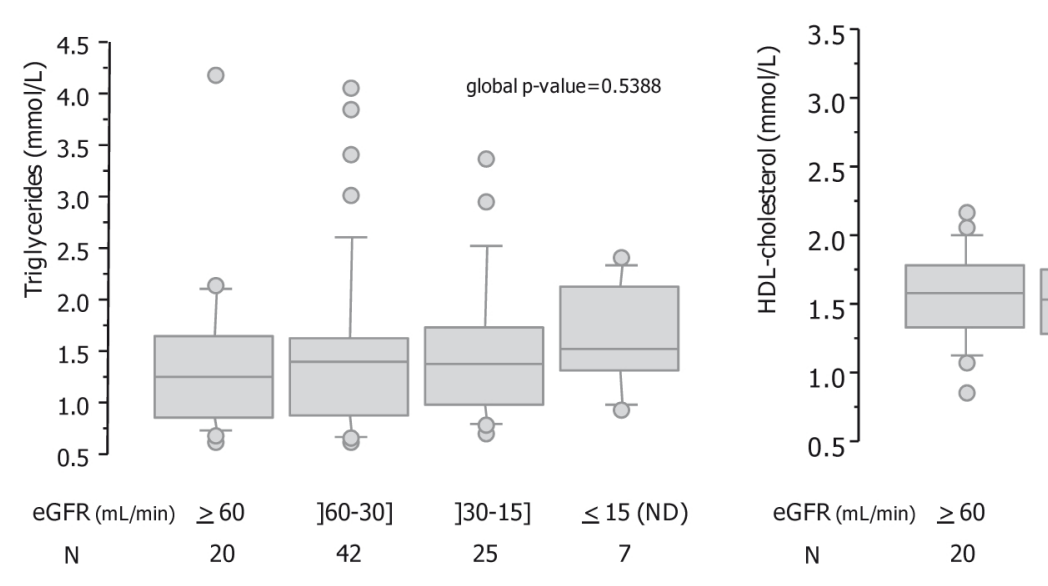

HDL-cholesterol
$\operatorname{eGFR}(\mathrm{mL} / \mathrm{min}) \geq 60$
$\mathrm{N}$

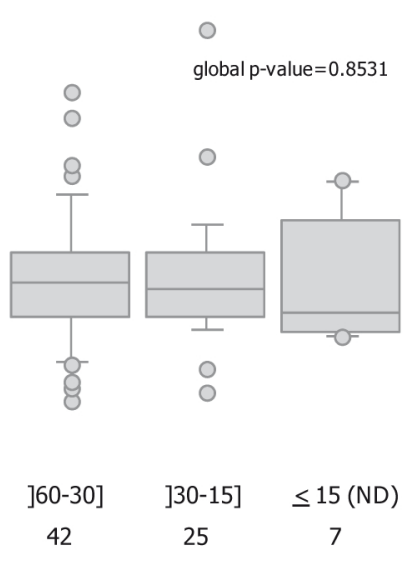

Lp(a)
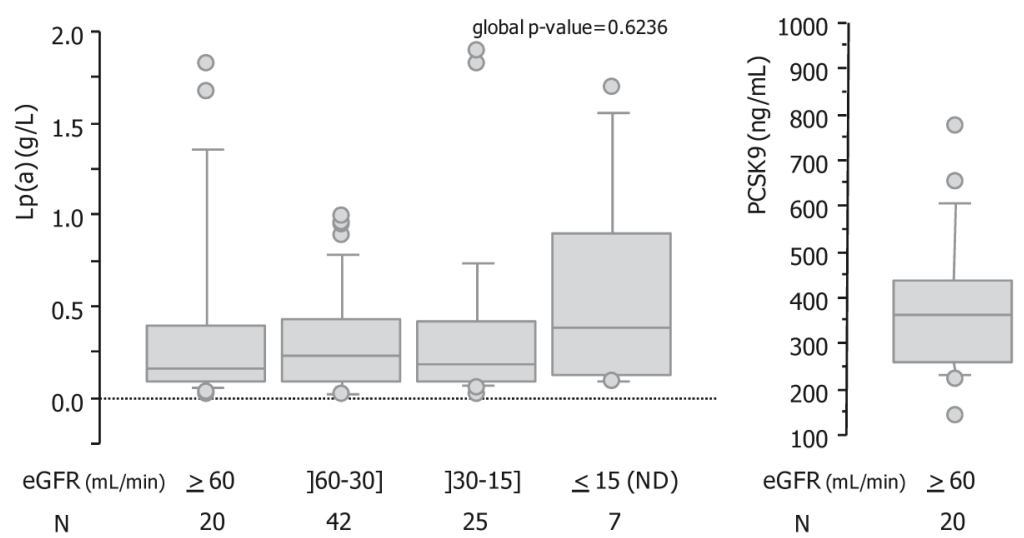

PCSK9
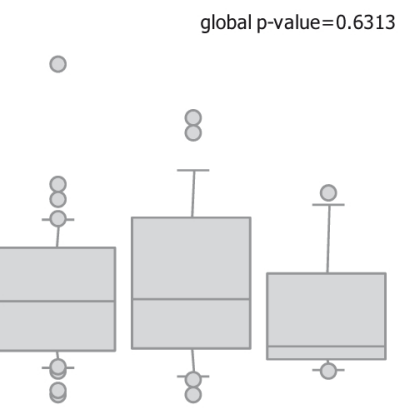

$\begin{array}{ccc}\text { 160-30] } & \text { ]30-15] } & \leq 15 \text { (ND) } \\ 42 & 25 & 7\end{array}$

Figure 2 Plasma PCSK9 and lipid parameters concentrations in ND-CKD patients not receiving statins. ND, not on dialysis.

PCSK9 and LDL-C for instance). Moreover, the sample size of ND-CKD patients with ESKD (with eGFR $\leq 15 \mathrm{~mL} / \mathrm{min}$ ) is small, and an additional larger study is warranted to further investigate the function of PCSK9 in this specific population (including patients under hemodialysis).
In conclusion, plasma PCSK9 is not associated to eGFR at several stages of CKD in nondiabetic patients without nephrotic proteinuria and without statin treatment. However, PCSK9 could be involved in TG-rich lipoprotein dysmetabolism observed in CKD. Further studies are necessary to confirm this hypothesis and to evaluate the 
Table 2 Associations between PCSK9 and lipid parameters in nondialysis chronic kidney disease patients $(n=94)$

\begin{tabular}{lcc}
\hline & \multicolumn{2}{l}{ PCSK9 $(\mathrm{ng} / \mathrm{mL})$} \\
\cline { 2 - 3 } & $\begin{array}{l}\text { Correlation } \\
\text { Coefficient (rho) }\end{array}$ & $P$ value \\
Variables & 0.187 & .0707 \\
\hline Total cholesterol (mmol/L) & 0.186 & .0751 \\
LDL cholesterol (mmol/L) & 0.192 & .0637 \\
Non-HDL cholesterol (mmol/L) & 0.221 & .0331 \\
Apo-B (g/L) & -0.048 & .6440 \\
HDL cholesterol (mmol/L) & 0.211 & .0416 \\
Triglycerides (mmol/L) & 0.187 & .0716 \\
Triglycerides/HDL cholesterol & 0.108 & .3023 \\
Lp(a) $(\mathrm{g} / \mathrm{L})$ &
\end{tabular}

Bold values are statistically significant.

LDL, low-density lipoprotein; HDL, high-density lipoprotein.

potential interest of anti-PCSK9 treatment in uremiarelated dyslipidemia.

\section{Acknowledgments}

Drs Cariou, Morena, and Cristol designed the study, supervised the analyses and wrote the paper. Dr Morena performed the statistical analyses. Le May and Arnaud performed the PCSK9 analyses. Drs Chenine, Dupuy, Pichelin, Leray-Moragues, Chenine, and Canaud performed study and data collection. All the authors have approved the final version of the article.

\section{Financial disclosures}

Dr Cariou has received research funding from Sanofi and Pfizer, received honoraria from AstraZeneca, Pierre Fabre, Janssen, Eli-Lilly, MSD Merck \& Co., Novo-Nordisk, Sanofi, and Takeda, and has acted as a consultant/advisory panel member for Amgen, Eli Lilly, Novo-Nordisk, MSD Merck \& Co, Sanofi, and Regeneron. The other authors state no conflict of interest.

\section{References}

1. Go AS, Chertow GM, Fan D, McCulloch CE, Hsu CY. Chronic kidney disease and the risks of death, cardiovascular events, and hospitalization. N Engl J Med. 2004;351(13):1296-1305.

2. Foley RN, Parfrey PS, Sarnak MJ. Clinical epidemiology of cardiovascular disease in chronic renal disease. Am J Kidney Dis. 1998; 32(Suppl 3):S112-S119.

3. Levey AS, de Jong PE, Coresh J, et al. The definition, classification, and prognosis of chronic kidney disease: a KDIGO Controversies Conference report. Kidney Int. 2011;80(1):17-28.

4. K/DOQI clinical practice guidelines for cardiovascular disease in dialysis patients. Am J Kidney Dis. 2005;45(4 Suppl 3):S1-S153.

5. Morena M, Jaussent I, Halkovich A, et al. Bone biomarkers help grading severity of coronary calcifications in non dialysis chronic kidney disease patients. PLoS One. 2012;7(5):e36175.
6. Rajman I, Harper L, McPake D, Kendall MJ, Wheeler DC. Low-density lipoprotein subfraction profiles in chronic renal failure. Nephrol Dial Transplant. 1998;13(9):2281-2287.

7. Cariou B, Le May C, Costet P. Clinical aspects of PCSK9. Atherosclerosis. 2011;216(2):258-265.

8. Abifadel M, Varret M, Rabes JP, et al. Mutations in PCSK9 cause autosomal dominant hypercholesterolemia. Nat Genet. 2003;34(2): $154-156$.

9. Cohen JC, Boerwinkle E, Mosley TH Jr., Hobbs HH. Sequence variations in PCSK9, low LDL, and protection against coronary heart disease. N Engl J Med. 2006;354(12):1264-1272.

10. Zhang XL, Zhu QQ, Zhu L, et al. Safety and efficacy of anti-PCSK9 antibodies: a meta-analysis of 25 randomized, controlled trials. BMC Med. 2015;13:123.

11. Lipinski MJ, Benedetto U, Escarcega RO, et al. The impact of proprotein convertase subtilisin-kexin type 9 serine protease inhibitors on lipid levels and outcomes in patients with primary hypercholesterolaemia: a network meta-analysis. Eur Heart J. 2016;37(6):536-545.

12. Li C, Lin L, Zhang W, et al. Efficiency and safety of proprotein convertase subtilisin/kexin 9 monoclonal antibody on hypercholesterolemia: a meta-analysis of 20 randomized controlled trials. J Am Heart Assoc. 2015;4(6):e001937.

13. Kwakernaak AJ, Lambert G, Slagman MC, et al. Proprotein convertase subtilisin-kexin type 9 is elevated in proteinuric subjects: relationship with lipoprotein response to antiproteinuric treatment. Atherosclerosis. 2013;226(2):459-465.

14. Sucajtys-Szulc E, Szolkiewicz M, Swierczynski J, Rutkowski B. Upregulation of liver Pcsk9 gene expression as a possible cause of hypercholesterolemia in experimental chronic renal failure. Mol Cell Biochem. 2016;411(1-2):281-287.

15. Haas M, Levenson A, Sun X, et al. The Role of Proprotein Convertase Subtilisin/Kexin Type 9 in Nephrotic Syndrome-Associated Hypercholesterolemia. Circulation. 2016;134(1):61-72.

16. Rogacev KS, Heine GH, Silbernagel G, et al. PCSK9 Plasma Concentrations Are Independent of GFR and Do Not Predict Cardiovascular Events in Patients with Decreased GFR. PLoS One. 2016;11(1): e0146920.

17. Abujrad H, Mayne J, Ruzicka M, et al. Chronic kidney disease on hemodialysis is associated with decreased serum PCSK9 levels. Atherosclerosis. 2014;233(1):123-129.

18. Konarzewski M, Szolkiewicz M, Sucajtys-Szulc E, et al. Elevated circulating PCSK-9 concentration in renal failure patients is corrected by renal replacement therapy. Am J Nephrol. 2014;40(2):157-163.

19. Costet P, Hoffmann MM, Cariou B, Guyomarc'h Delasalle B, Konrad T, Winkler K. Plasma PCSK9 is increased by fenofibrate and atorvastatin in a non-additive fashion in diabetic patients. Atherosclerosis. 2010;212(1):246-251.

20. Cariou B, Le Bras M, Langhi C, et al. Association between plasma PCSK9 and gamma-glutamyl transferase levels in diabetic patients. Atherosclerosis. 2010;211(2):700-702.

21. Lakoski SG, Lagace TA, Cohen JC, Horton JD, Hobbs HH. Genetic and metabolic determinants of plasma PCSK9 levels. J Clin Endocrinol Metab. 2009;94(7):2537-2543.

22. Costet P, Cariou B, Lambert G, et al. Hepatic PCSK9 expression is regulated by nutritional status via insulin and sterol regulatory element-binding protein 1c. J Biol Chem. 2006;281:6211-6218.

23. Goolsby MJ. National Kidney Foundation Guidelines for chronic kidney disease: evaluation, classification, and stratification. $J$ Am Acad Nurse Pract. 2002;14(6):238-242.

24. KDIGO 2012 Clinical Practice Guideline for the Evaluation and Management of Chronic Kidney Disease. Kidney Int Suppl. 2013;3(1): $1-150$.

25. Boutten A, Bargnoux AS, Carlier MC, et al. Enzymatic but not compensated Jaffe methods reach the desirable specifications of NKDEP at normal levels of creatinine. Results of the French multicentric evaluation. Clin Chim Acta. 2013;419:132-135.

26. Levey AS, Stevens LA, Schmid CH, et al. A new equation to estimate glomerular filtration rate. Ann Intern Med. 2009;150(9):604-612. 
27. Chronic kidney disease: early identification and management of chronic kidney disease in adults in primary and secondary care. NICE Natl Inst Health Care Excell. 2014 Clinical Guideline 182.

28. Kuster N, Cristol JP, Cavalier E, et al. Enzymatic creatinine assays allow estimation of glomerular filtration rate in stages 1 and 2 chronic kidney disease using CKD-EPI equation. Clin Chim Acta. 2014;428: 89-95.

29. Dubuc G, Chamberland A, Wassef H, et al. Statins upregulate PCSK9, the gene encoding the proprotein convertase neural apoptosisregulated convertase-1 implicated in familial hypercholesterolemia. Arterioscler Thromb Vasc Biol. 2004;24(8):1454-1459.

30. Jin K, Park BS, Kim YW, Vaziri ND. Plasma PCSK9 in nephrotic syndrome and in peritoneal dialysis: a cross-sectional study. Am J Kidney Dis. 2013;63(4):584-589.

31. Lambert G, Jarnoux A, Pineau T, et al. Fasting induces hyperlipidemia in mice overexpressing proprotein convertase subtilisin kexin type 9: lack of modulation of very-low-density lipoprotein hepatic output by the low-density lipoprotein receptor. Endocrinology. 2006;147(10): 4985-4995.

32. Herbert B, Patel D, Waddington S, et al. Increased secretion of lipoproteins in transgenic mice expressing human D374Y PCSK9 under physiological genetic control. Arterioscler Thromb Vasc Biol. 2010; 30(7):1333-1339.

33. Ouguerram K, Chetiveaux M, Zair Y, et al. Apolipoprotein B100 metabolism in autosomal-dominant hypercholesterolemia related to mutations in PCSK9. Arterioscler Thromb Vasc Biol. 2004;24(8): $1448-1453$.

34. Cariou B, Langhi C, Le Bras M, et al. Plasma PCSK9 concentrations during an oral fat load and after short term high-fat, high-fat highprotein and high-fructose diets. Nutr Metab (Lond). 2013;10(1):4.

35. Sucajtys-Szulc E, Szolkiewicz M, Swierczynski J, Rutkowski B. Upregulation of Hnflalpha gene expression in the liver of rats with experimentally induced chronic renal failure - A possible link between circulating PCSK9 and triacylglycerol concentrations. Atherosclerosis. 2016;248:17-26.

36. Batista MC, Welty FK, Diffenderfer MR, et al. Apolipoprotein A-I, B100, and B-48 metabolism in subjects with chronic kidney disease, obesity, and the metabolic syndrome. Metabolism. 2004;53(10): $1255-1261$.

37. Twisk J, Gillian-Daniel DL, Tebon A, Wang L, Barrett PH, Attie AD. The role of the LDL receptor in apolipoprotein B secretion. J Clin Invest. $2000 ; 105(4): 521-532$. 